\title{
HONOR KILLING OF WOMEN: A COMPARATIVE STUDY OF THE PAKISTANI PRINT MEDIA
}

\author{
SYED HASSAN RAZA $^{1} \&$ MAHMOONA LIAQAT $^{2}$ \\ ${ }^{1}$ School of Multimedia Technology \& Communication, Universiti Utara Malaysia \\ ${ }^{1}$ Bahauddin Zakariya University Multan. Pakistan. \\ Email: hassansherazi@bzu.edu.pk \\ ${ }^{2}$ Communication Studies Bahauddin Zakariya University Multan. Pakistan
}

\begin{abstract}
This research examines news coverage on honor killing. This study is the comparative study of the two mainstream print media outlets Jang and Khabrain. The time period has been chosen from January 2013 to March 2013. Content analysis was used to examine how honor killing news is presented in these two newspapers. this exploration about the honor killing news especially violence news about the women further advance the dynamics of the crime news reporting by gathering the useful information that how the reporters and the media agenda setters are treating this issue. Six main categories and five hypotheses were developed and tested. This research focused on how much print media of Pakistan gave importance to the news of honor killing. The social evils are highlighted in the press, dealing various issues about women, including the honor killing, like arranged marriage, Love marriage, victim statement, Mal-practice, victims of the Sexual assault, Karo-Kari. Murder is another evil against women. The stone-hearted people kill the innocent women when they feel they are the shame for them.
\end{abstract}

Key words: Arrange marriage, Love marriage, victims statement, Mal-practice, victims of Sexual assault, Karo-Kari.

Introduction. The honor killing is most often defined as a reaction to the belief that a females or teenager girls has dishonored her family's will usually because of the perceptions of sexual rudeness [18]. Families position men to watch their family honor and one of the marks of honor killing is that they are planned by family councils rather than individual family members. Honor killing is common in the Middle East, North Africa, and parts of Asia, as well as South America. This phenomenon also seen in the communities of the Pakistan in the recent history such kind of the incidence reported in the media. Media outlets some time give them coverage as the main item for their breaking stories and follow up the issues as well [14][17]. This kind of media reports also play critical role in the awareness of the general public hence, it also highlights the darker side of the social taboos. By the means of reporting such issues media also sometime face criticism from the some of the media critics.

Moreover, what differentiates honor murder from ordinary, family violence is that the fault is often decided by the family as a whole it is deliberate and a performer is appointed on the basis of given criteria and is treated with respect and pride by the family [11]. Restoring the family's honor washing away the shame is seen as a social responsibility and the right of the insulted groups the family and relatives. The misdeed is often met with understanding and silent getting by the local community a village or ethnic group, however, the mainstream media reports now a days serve as the vocal tool to bring these issues on the societal level [7][17]. Hence, in some cases both men and women are subject to honor killings, but mostly media critics has the view that media present the women as the victim. Recently, the honor killing is well documented in the media of the Pakistan like the other countries e.g. Turkey, European countries, 
which give the opportunity to the public to debate this issue at the street level and consider as the opinion building nucleus for the among general public.

The practice of the honor killing is not limited to Pakistani culture. Though, it is also evident across the world. However, it retains a long history and links to the appearance of patriarchal social structures across Europe and Asia. Amongst the reasons behind this phenomenon as are of the same nature to some extent [1]. For instance, the determination of honor killing in Sindh has been revealed in recent history get motivation from the tribal feudal structure. There are many other reason reportedly. However, in the current study it is aim to determine that how much coverage of to the honor killing news is given in the mainstream print media outlets such as Jang and Khabrain in Pakistan. Among the other main purposes of the current study to query of how much coverage is given to the stance of victims and frequency of honor killing of men and women in these two newspapers. This contribution makes the current study significant as it remains unclear in the previous studies [8][10].

Furthermore, as every newspaper is having its own policy. Therefore, some newspaper desires to project political news, while others want to highlight accidental and crime news. Even, if we say that English and Urdu newspapers are working on different policies than it will also right. Moreover, the English dailies carrying more governmental and international news. While the Urdu dailies mostly concern with crime news and honor killing news. The issue which are concerned to women are mostly projected by newspapers. Here, the current research is centered on the women. Relationally, this exploration about the honor killing news especially violence news about the women further advance the dynamics of the crime news reporting. Firstly, by gathering the useful information that how the reporters and the media agenda setters are treating this issue. Secondly, as the crime ration in our society is going up day by day the media outlets also highlighting certain dynamics of this issue. Among them the most sensitive issue which can distort the image of the whole society is the honor killing. However, most of the space in our national newspapers is occupied by that news in which women are severely beaten up by her husband or in laws and in the end is burnt by them or somewhere women are held by some person and become the victim of rape [4]. Therefore, potentially such kind of the reporting may have certain impacts on the general public as well. Therefore, the current study is an initial level exploration tempted to find out the intensity of this most sensitive issue that it can contribute the literature by giving the essential information about the coverage related to honor killing.

Literature review. There are many recent studies stated that honor killing is supported by custom and it could be seen North Africa, Middle East including Turkey and Pakistan [6][7]. The honor murder is also known as Karo-Kari. Karo (Black male) and Kari (Black female). Karo-Kari is the murder of male or female which cause the dishonor of the family. Four provinces of Pakistan influenced by honor killing. It is analyzed that one thousand females murdered previous year [3]. Female were murdered because they were against the family decisions'-Kari is a bad tradition by which the growth and live hood of young generation is affected.472 cases of honor murder were registered in 2009 among them 91 from Punjab,220 from Sindh,32 from KPK, 127 from Baluchistan and 2 from Islamabad.

Many studies stated that honor killing is an act of violence which gives female the cause of to live under the banner of honor [5][12]. Many studies discussed that the assimilation of honor with different beliefs and religion have led it to the different practices linked with honor. The concept of honor is varying in different societies. In countries like Middle east honor murder is the important part of the society [15]. Generally, honor is linked with social position of an individual or a whole family. Actually the honor is the reputation of a person or the whole family in the eyes of society. It is the pride of an individual or a family. So that's why there is a deep attachment between an individual or a family with its honor. In Turkey, there is a very famous saying, people live for their honor.

It is indicated in the previous studies that in Pakistan the honor killing has taken an alarmingly high proportion of incident in recent year [9][13]. According to Aurat Foundations in 2010,557 females were killed in the name of honor killing, while604 females were killed in the year of 2009 and the number of women killed in year 2008 were 475.In several cases the jirgahs and panchayats declared women and men guilty of karo-kari and siah-kari and punished them death. Criminal law act 2004, which is also known as honor killing act, provide protection to all the citizens especially young girls and women. In some recent studies it is analyzed that honor killing is a belief deeply rooted in culture which consider female as object and commodities[6][7]. According to this concept female are the property of male. Male and female has a special importance in those cultures where honor killing take place. Females are considering as responsible for the honor of the family. The person who committed the murder in the name of honor killing often speak 
with defiant pride and without guilty on their actions. A Jordan 22-year young boy name Wafik Abu Abseh, who had committed a so called honor killing said that, we do not consider it a murder [7].

Some authors like discussed that honor killing is culturally and legally acceptable in countries like Turkey, Jordan or Pakistan [3][11][14]. In western European areas the number of honor crime are increasing. This crime is often ignored by the state and the law enforcement agencies and court. In the British court the murdered tries to hide his crime under the religious ground. The case of honor killing should be taken like the other murder. The proper training should be given to law enforcement agencies to avoid the further killings. Punishment should be given to the murdered. Some studies observed that economic crisis or conflicts are also the cause of increase in the cases of honor killings [2][16]. A female who is threatened by honor killing by her family is discriminated not only on the base of gender but also on the basis of racial and gender prejudice if she wants help from the police. It is difficult to find the total numbers of female which are killed every year in world.

When the women read about such news they feel insecurity. They think they go out, anything may go wrong. The feelings of insecurity generate tension among them. What so ever is being published in the newspapers with the reference of crime/honor killing become the major cause of frustration and tension among women. Psychologists agree that tension is the basic element in generating different mental disorders like psychosis and neuroses, sometimes, tension not only effects the mind but the physical health too. Consequently, the immediate reaction especially the news related to the honor killing is in a form of tension. If such a large and important portion of our society get the such kind of coverage which is not ethically derived it can disturb their daily routines and can have severe effects on them. That's why it is need to investigate that how much coverage has been given in the leading newspapers such as Jang and Khabrain to the honor killing. Jang and Khabrain are the most popular newspapers in Pakistan. People consider them among the most credible newspaper in Pakistan. Whereas, the other newspaper selected for the current study is Khabrain, blamed to promote the yellow journalism. These newspapers have high circulation and are the most popular newspapers among the upper class and middle class that's why the current study gives the comparison between these two newspaper to advance the literature in this direction that it may provide the explored nature of the coverage regarding this sensitive issue.

Hypothesis:

H1: It is more likely that Arranged marriage are more in Jang than Khabrain.

$\mathrm{H} 2$ : It is more likely that Love marriage are more in Khabrain than Jang.

H3: It is more likely that victim statements are more in Jang than Khabrain.

H4: It is more likely that Mal-practice more in Jang than Khabrain.

H5: It is more likely that victim of sexual assault is more in Khabrain than Jang.

Research Methodology: The study aimed at analyzing coverage of honor killing news in daily Jang and daily Khabrian. The researcher chooses the content analysis as research design for this particular research. Keeping in view the nature of topic, technique of content analysis is applied in order to accomplish the research study. The news items published on whole newspapers in daily Jang and daily Khabrian from $1^{\text {st }}$ January 2013 to March $31^{\text {st }}, 2013$ about the coverage of honor killing were decided on the universe of the research. Therefore, the two leading newspapers daily Jang and daily Khabrian are the universe of the study. These two dailies were selected as a sample because of their large readership. In this research census sampling is adopted by the researcher. Firstly, a pilot study of three months was conducted and on the basis of results every day of a week is selected to collect the data. The total number of honor killing related news published in the two dailies from January 2013 to March 2013. All news stories which are related to honor killing in both dailies. The news of the honor killing is categorized into the following categories such as arranged marriage, love marriage, victim statement, mal-practice, sexual assault, karo-kari. 


\section{Data Analysis}

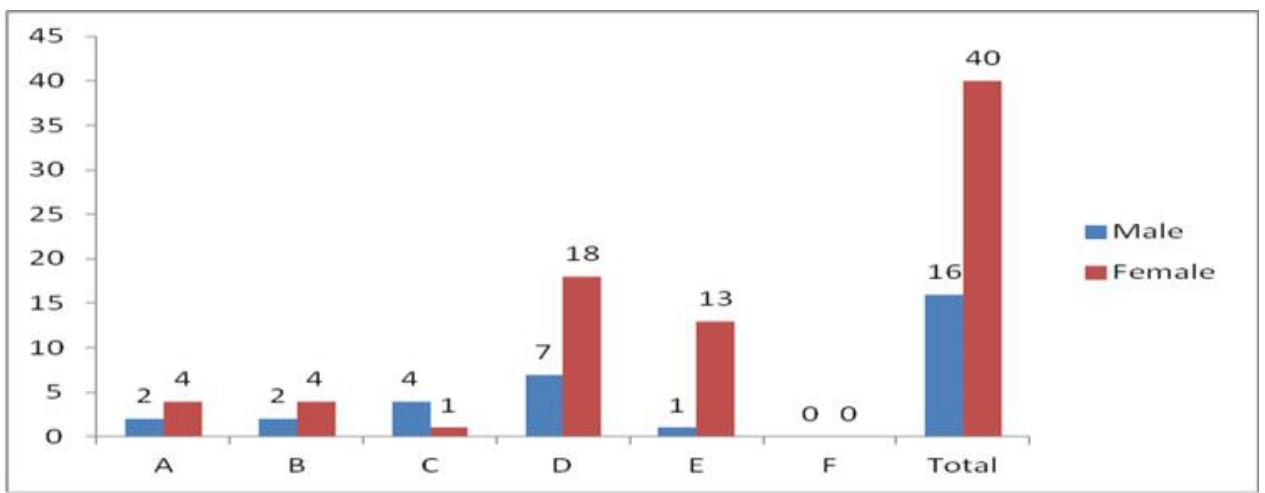

Figure 1. Analysis based on Jung newspaper

In the month of January, February and March, there were total 56 news about honor killing among which 40 news were about the female and 16 about the male. Total news about arrange marriage were 6 . Four were related to female and two news related to male. Total 6 news related to love marriage from which 4 were related to female while 2 was related to male. Total 5 news related to victim statement from which 4 related to male while 1 news was related to female. There were 25 news about the Mal-Practice in Jang newspaper in following months from which 18 news were related to female while 7 was related to male. There were 14 news about victim of sexual assault in Jang newspaper during following month from which 13 news were related to female while 1 was related to male. Moreover, there was no news about Karo-kari in Jang newspaper during following months as shown in the Figure 1.

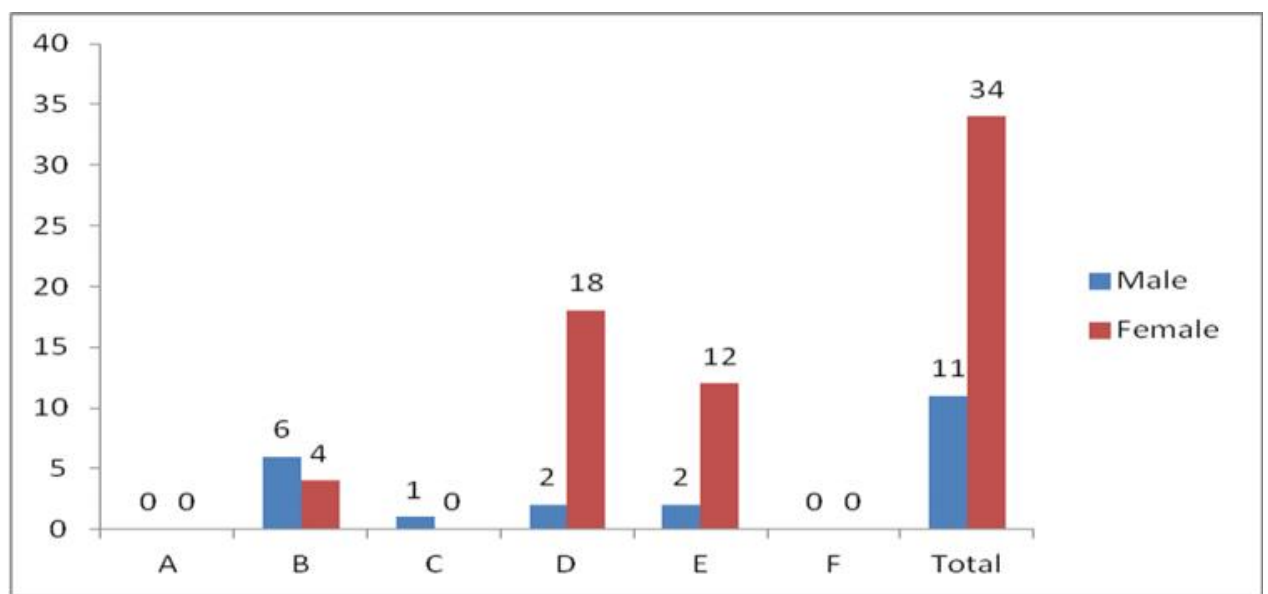

Figure 2. Analysis based on Khabrain newspaper

In the month of January, February and march, there were total 45 news about honor killing among which 34 news were about the female and 11 about the male. There was no news about arrange marriage in Khabrain newspaper during following month of January. Total 10 news about love marriage from which 4 were related to female while 6 were related to male. There was only 1 news about victim statement from which was related to male. Total 20 news about Mal practice from which were 18 related to female and only 2 related to male. Total news about victim of sexual assault were 14 among which 12 were related to female and 2 news related to male. There was no news about Karo-Kari in Khabrain newspaper during following month of January as shown in the Figure 2. 
Table 1. Categories data in Jung and Khabrain newspapers for three months

\begin{tabular}{|c|c|c|c|c|c|c|c|c|c|c|c|c|c|}
\hline \multirow{6}{*}{ Jang } & \multirow{2}{*}{ Month } & \multicolumn{2}{|c|}{ A } & \multicolumn{2}{|l|}{ B } & \multicolumn{2}{|l|}{$\mathrm{C}$} & \multicolumn{2}{|c|}{ D } & \multicolumn{2}{|l|}{$\mathrm{E}$} & \multicolumn{2}{|l|}{$\mathrm{F}$} \\
\hline & & $\mathrm{F}$ & M & $\mathrm{F}$ & M & $\mathrm{F}$ & M & $\mathrm{F}$ & M & $\mathrm{F}$ & M & $\mathrm{F}$ & M \\
\hline & Jan & 3 & 0 & 2 & 1 & 1 & 3 & 5 & 3 & 6 & 1 & 0 & 0 \\
\hline & Feb & 0 & 0 & 1 & 0 & 0 & 1 & 6 & 3 & 2 & 0 & 0 & 0 \\
\hline & March & 1 & 2 & 1 & 1 & 0 & 0 & 7 & 1 & 5 & 0 & 0 & 0 \\
\hline & Total & 6 & & 6 & & 5 & & 25 & & 14 & & 0 & \\
\hline & Jan & 0 & 0 & 4 & 2 & 0 & 1 & 8 & 1 & 6 & 0 & 0 & 0 \\
\hline & Feb & 0 & 0 & 0 & 1 & 0 & 0 & 3 & 0 & 4 & 0 & 0 & 0 \\
\hline & March & 0 & 0 & 0 & 3 & 0 & 0 & 7 & 1 & 2 & 2 & 0 & 0 \\
\hline & Total & 0 & & 10 & & 1 & & 20 & & 14 & & 0 & \\
\hline
\end{tabular}

Conclusion. Overall the research is about the News coverage on honor killing, A comparative study of Jang and Khabrain. 4 hypotheses have been approved and 1 is equal. There is 56 news about honor killing in Jang newspaper from which 40 news were related to female and 16 were related to male. 45 news were about honor killing in Khabrain newspaper among which 34 news were about the female and 11 about the male. The first hypothesis was about Arranged marriage. When a woman goes against the decision of marriage taken by her parents than the parents as the reaction kill her. There was total 6 news in Jang newspaper about Arranged marriage but there was no news like that in Khabrain. The second hypothesis was about Love marriage. When a women do the marriage of her own will than her parents and other family members kill her. The results proved that second hypothesis is also valid as there was 6 news in Jang and 10 news in Khabrain. The third hypothesis was about victim's statement. The viewpoint of the people who become the victims of honor killing. This hypothesis is verified by the findings of the study that 5 news in Jang and only 1 news in Khabrain. The fourth hypothesis was that Mal-practice. If women break the norms and values of her family than the family members kill her to save the owner of her family. In most of the cases, women are killed in doubt of Malpractice. This hypothesis is supported by the findings of the study that 25 news in Jang and 20 news in Khabrain. The fifth hypothesis was that victim of sexual assault. If a woman, unfortunately, become the victim of sexual assault than the parents kill her to save the honor of their family. So news victims of sexual assault about honor killing are equal both in Jang 14 and Khabrain 14. The results indicate that there is a high frequency of the honor killing reported issues in the newspaper of the Pakistan. Therefore, it is suggested that future studies must adopt the qualitative approach to identify the themes of these news that they may suggest some ethical guidelines for the reporters in the field.

\section{REFERENCE}

[1]. Abu-Odeh, L. (2011). Crimes of honor and the construction of gender in Arab societies. Comparative Law Review. http://doi.org/10.5131/ajcl.2010.0007

[2]. Ahmetbeyzade, C. (2008). Gendering Necropolitics: The Juridical-Political Sociality of Honor Killings in Turkey. Journal of Human RIghts, 7(3), 187-206.

[3]. Baker, N. V., Gregware, P. R., \& Cassidy, M. a. (1999). Family Killing Fields: Honor Rationales in the Murder of Women. Violence Against Women, 5(2), 164-184.

[4]. Cihangir, S. (2012). Gender specific honor codes and cultural change. Group Processes \& Intergroup Relations, 16(3), 319-333. 
[5]. Crook, Z. (2009). Honor, shame, and social status revisited. Journal of Biblical Literature, 128(3), 591-611.

[6]. Do an, R. (2014). Different Cultural Understandings of Honor That Inspire Killing: An Inquiry Into the Defendant's Perspective. Homicide Studies, (43), 1088767914526717 http://doi.org/10.1177/1088767914526717

[7]. Eisner, M., \& Ghuneim, L. (2013). Honor killing attitudes amongst adolescents in Amman, Jordan. Aggressive Behavior, 39(5), 405-417.

[8]. Fischer, J. (2011). Honor Code: How Moral Revolutions Happen - By Kwame Anthony Appiah. Journal of Applied Philosophy, 28(1), 96-99.

[9]. Kidwai, R. (2002). Domestic violence in Pakistan: The role of patriarchy, gender roles, the culture of honor and objectification/commodification of women. ProQuest Information \& Learning.

[10]. Korteweg, A., \& Yurdakul, G. (2009). Islam, gender, and immigrant integration: boundary drawing in discourses on honour killing in the Netherlands and Germany. Ethnic and Racial Studies, 32(2), 218 238.

[11]. Kulwicki, A. D. (2002). The practice of honor crimes: a glimpse of domestic violence in the Arab world. Issues in Mental Health Nursing, 23(1), 77-87. http://doi.org/10.1080/01612840252825491

[12]. Maris, C., \& Saharso, S. (2001). Honour killing: A reflection on gender, culture and violence. Netherlands' Journal of Social Sciences Vol 37(1) 2001, 52-73.

[13]. Raza, S. H., \& Hussain, S. S. (2016). News Coverage of Physical Violence against Women: Where Do We Position. Journal of Culture, Society and Development, 19, 75-81.

[14]. Reimers, E. (2007). Representations of An Honor Killing. Feminist Media Studies, 7(3), 239-255.

[15]. van Osch, Y., Breugelmans, S. M., Zeelenberg, M., \& Boluk, P. (2013). A Different Kind of Honor Culture: Family Honor and Aggression in Turks. Group Processes \& Intergroup Relations, 16(3), 334-344.

[16]. Vitoshka, D. Y. (2010). The Modern Face of Honor Killing: Factors, Legal Issues, and Policy Recommendations. Berkeley Undergraduate Journal, 22(2).

[17]. Welden, B. a. (2010). Restoring lost "honor": Retrieving face and identity, removing shame, and controlling the familial cultural environment through "honor" murder. Journal of Alternative Perspectives in the Social Sciences, 2(1), 380-398.

[18]. Wynn, L. L. (2013). Honor killing. Anthropology and Humanism, 38(2), 187-200. 